\title{
Effect of alumina coating and extrusion deformation on microstructures and thermal properties of short carbon fibre-Al composites
}

\author{
YU HUANG ${ }^{1, *}$, QIUBAO OUYANG ${ }^{1}$, CHENGNAN ZHU ${ }^{1}$, JING ZHU ${ }^{2}$, GUODING ZHANG ${ }^{1}$ and \\ DI ZHANG ${ }^{1}$ \\ ${ }^{1}$ State Key Laboratory of Metal Matrix Composites, Shanghai Jiao Tong University, Shanghai 200240, \\ People's Republic of China \\ ${ }^{2}$ Shanghai Composites Science and Technique Co., Ltd, Shanghai 201112, People's Republic of China \\ *Author for correspondence (huangyu5044@sjtu.edu.cn)
}

MS received 9 August 2016; accepted 21 December 2017; published online 5 February 2018

\begin{abstract}
Short carbon fibres were coated with alumina by sol-gel process. Uncoated and alumina-coated short carbon fibre-Al composites were fabricated by gas pressure infiltration process. The effects of alumina coating and extrusion deformation on microstructures and thermal properties of the composites were studied. The results show that alumina coating is effective to improve the quality of the short carbon fibre preform as well as act as diffusion barrier to impede interfacial harmful chemical reactions between aluminium and short carbon fibres, which would increase the thermal properties of the composites. Extrusion deformation can orient the carbon fibres to the extrusion direction to improve their degree of orientation, meanwhile decreasing their aspect ratio. Extrusion deformation has a beneficial effect on the thermal conductivity of the composites. However, its effect on coefficient of thermal expansion of the composites is small because the effects of the improvement in degree of orientation and the decrease of aspect ratio tend to cancel each other somewhat.
\end{abstract}

Keywords. Carbon fibre; aluminium composite; alumina coating; extrusion; thermal properties.

\section{Introduction}

Carbon fibres are excellent reinforcements in polymer, metal as well as ceramic materials due to their outstanding mechanical and thermal properties [1-3]. Carbon fibre composites are promising materials for applications in aerospace, thermal management and automobiles because of their low density, high strength and stiffness, low coefficient of thermal expansion (CTE) and/or high thermal conductivity (TC) [1-6]. Carbon-fibre-reinforced polymer matrix composites are already used extensively in the aforementioned areas, but carbon-fibre-reinforced metal matrix composites have not reached that stage yet, due to some fabrication problems [5]. For example, short-carbon-fibre-reinforced aluminium (SCF-Al) composites are low-cost materials with good processability and designable fine thermal and mechanical properties that can find applications in the aerospace, thermal management and automobiles [7,8]. However, the development of SCF-Al composites has been hindered by some fabrication problems such as the harmful chemical reactions between carbon fibres and aluminium as well as the orientation control of SCFs [6-10].

For $\mathrm{SCF}-\mathrm{Al}$ composites, it is widely accepted that carbon fibres would react with aluminium to form brittle $\mathrm{Al}_{4} \mathrm{C}_{3}$, which is harmful to both mechanical and thermal properties of the composites [11-14]. An effective method to solve this problem is to coat the carbon fibres with protection coatings [11-15]. Among all the coatings being considered in carbon fibre-reinforced aluminium ( $\mathrm{CF}-\mathrm{Al})$ composites, alumina coating has attracted much attention due to the fact that it can act as diffusion barrier to impede interfacial reactions [16-19]. Some researchers have reported that alumina coating has beneficial effects on mechanical properties of $\mathrm{CF}-\mathrm{Al}$ composites [16-18]. However, there are few studies about the effect of alumina coating on thermal properties of $\mathrm{CF}-\mathrm{Al}$ composites.

Carbon fibres have anisotropic properties [1]. They possess excellent properties along the fibre direction while the properties along the cross-section directions are relatively poor. Therefore, in order to bring the reinforcing effect of carbon fibres into full play, it is very important to control the orientation of the carbon fibres in SCF-Al composites. Many researchers tried to control the orientation of carbon fibres by fabricating SCF preforms with preferred orientation by wet-forming process and later infiltrating by liquid aluminium $[6,7,20]$. However, due to the spring back effect of the carbon fibres [7], the orientations of carbon fibres in composites fabricated by this method would not orient as expected $[6,7,20]$. So far, few researchers have used secondary deformation to control the orientation of carbon fibres. Actually, 
deformations such as extrusion can orient the carbon fibres to the extrusion directions. Therefore, the effect of extrusion deformation on properties of SCF-Al composites is an interesting issue of SCF-Al composites.

This work aims to explore the effect of alumina coating and extrusion deformation on thermal properties of the composites. In particular, the coating processes of alumina coating were optimized and beneficial effect of alumina coatings on thermal properties of the composites was found and explained. The effect of extrusion deformation on microstructures and thermal properties of the composites was exposed.

\section{Materials and methods}

\subsection{Raw materials}

Low-cost PAN-based carbon fibres (Shanghai Carbon Co. Ltd., China) with average diameters of $7 \mu \mathrm{m}$ and average length of $100 \mu \mathrm{m}$ were used in this study. AC4C aluminium alloy was chosen as the matrix in this study.

\subsection{Preparation of fibre coatings}

The fibre coatings were fabricated by a sol-gel method. Aluminium nitrate (Analytical Reagent, A.R.) and ammonia solution (A.R.) were used as the starting materials. The transparent boehmite sol was prepared as follows: ammonia solution $\left(1 \mathrm{~mol} \mathrm{l}^{-1}\right)$ was dripped into aluminium nitrate solution $\left(1 \mathrm{~mol}^{-1}\right)$ at a speed of 100 drips $\min ^{-1}$ with rapid stirring. After the completion of precipitation, the solution became milk-like. Afterwards, the milk-like solution was first filtrated, washed by distilled water, dried and then dissolved in distilled water. Thereafter, with the addition of some nitric acid and polyvinyl alcohol (PVA) solutions, the solution was heated for $2 \mathrm{~h}$ at $90^{\circ} \mathrm{C}$ with vigorous stirring in order to obtain the homogeneous transparent sol. Before the coating process, the carbon fibres were pre-heated at $400^{\circ} \mathrm{C}$ for $30 \mathrm{~min}$ to remove the sizing resin and induce pits that may help the solgel adsorption. The pre-heated carbon fibres were first dipped into the boehmite sol for $10 \mathrm{~min}$, then filtrated and dried at $50^{\circ} \mathrm{C}$ for $6 \mathrm{~h}$ and finally calcined at $1000^{\circ} \mathrm{C}$ to obtain alumina coatings in argon atmosphere.

\subsection{Preparation of composites}

The preparation processes of SCF-Al composites are schematically illustrated in figure 1. SCFs were dispersed in a PVA solution with some acid phosphate binders and then wet SCF preforms were produced by wet-forming. To obtain aluminacoated SCF preforms, SCFs were dispersed in the boehmite sol followed by wet-forming. Figure 2 a shows the differential scanning calorimetry (DSC) and thermogravimetric analysis (TGA) results of the as-received SCFs, SCF preforms and alumina-coated SCF preforms from room temperature to $1000^{\circ} \mathrm{C}$. All of them have an endothermic peak at $100-150^{\circ} \mathrm{C}$, which is due to the evaporation of water. The exothermic peak of the DSC curve of the as-received SCFs at $400-500^{\circ} \mathrm{C}$ is caused by the decomposition of the sizing resin on the surface of the SCFs. For SCF preforms, the exothermic peak in the range of about $200-800^{\circ} \mathrm{C}$ is caused by the phase change of the acid phosphate binders (from aluminium hydrogen phosphate $\mathrm{Al}\left(\mathrm{H}_{2} \mathrm{PO}_{4}\right)_{3}$ to aluminium metaphosphate $\left.\mathrm{Al}\left(\mathrm{PO}_{3}\right)_{3}\right)$ [21]. For alumina-coated SCF preforms, an exothermic peak ranging from 200 to $950^{\circ} \mathrm{C}$ can be detected, which is caused by phase change of boehmite to $\gamma-\mathrm{Al}_{2} \mathrm{O}_{3}$ and the decomposition of PVA [16-18]. Also, a small exothermic peak at about $1000^{\circ} \mathrm{C}$ was found for this DSC curve, which is probably

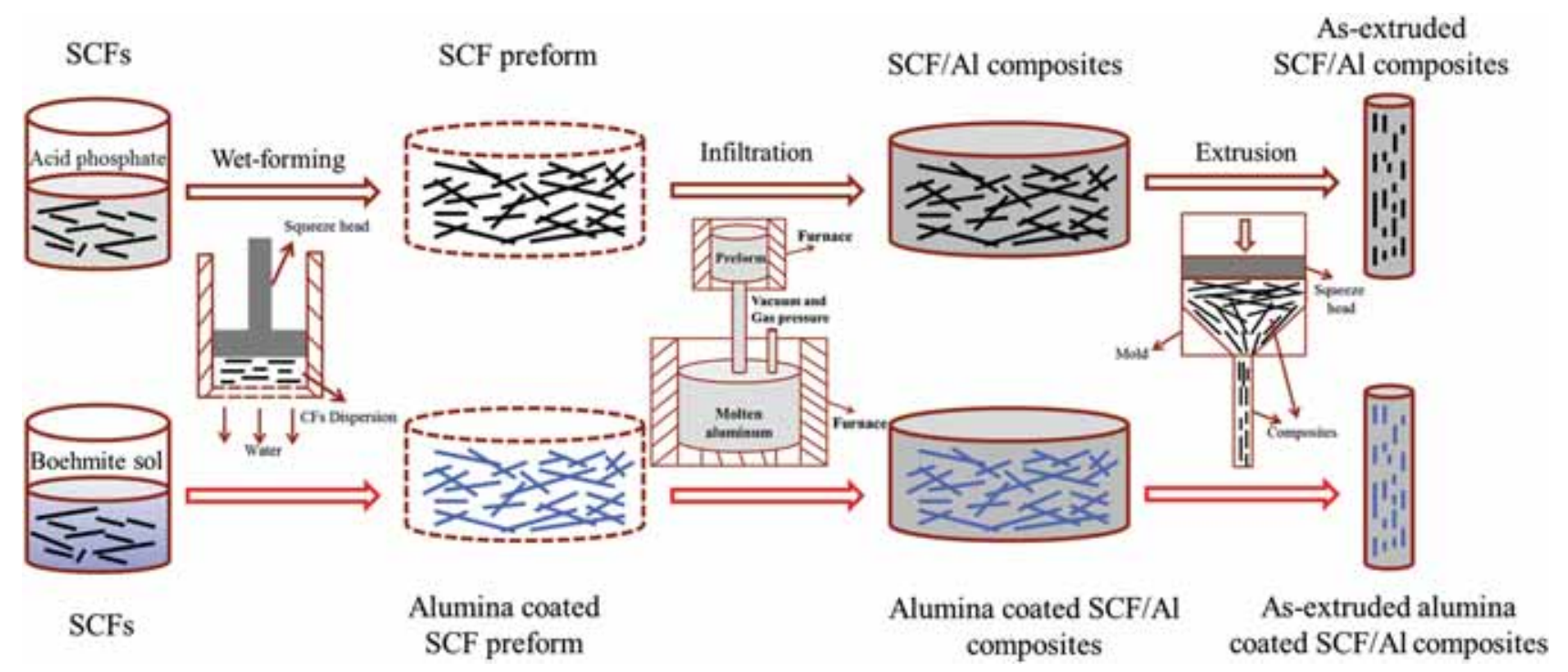

Figure 1. Schematic diagram of the preparation processes of $\mathrm{SCF}-\mathrm{Al}$ and alumina-coated $\mathrm{SCF}-\mathrm{Al}$ composites. 

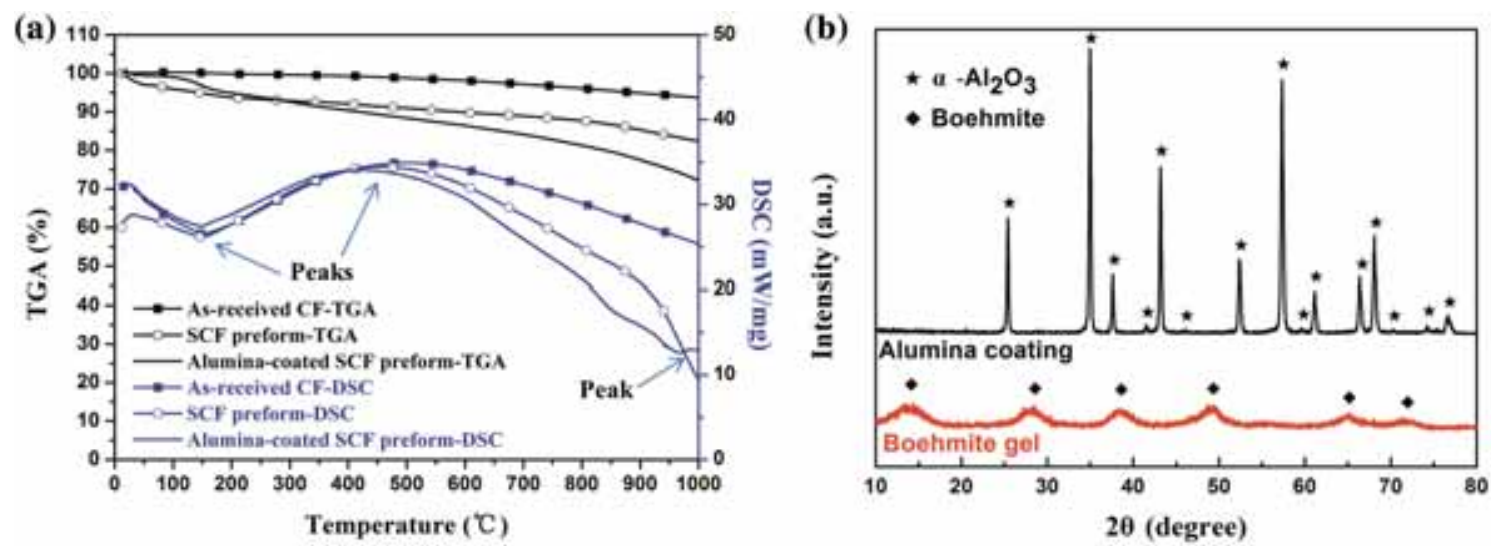

Figure 2. (a) TGA-DSC curves of as-received SCF, SCF preform and alumina-coated SCF preforms and (b) XRD profiles of the boehmite gel and alumina coating.

caused by the phase change of $\gamma-\mathrm{Al}_{2} \mathrm{O}_{3}$ to $\alpha-\mathrm{Al}_{2} \mathrm{O}_{3}$ [16-18]. Therefore, the SCF preforms were heat treated at $800^{\circ} \mathrm{C}$ for $2 \mathrm{~h}$ to obtain SCF preforms with sufficient strength [21]. The alumina-coated SCF preforms were heat treated at $1000^{\circ} \mathrm{C}$ for $2 \mathrm{~h}$ to obtain alumina-coated SCF preforms with sufficient strength. The SCF-Al and alumina-coated SCF-Al composites were fabricated by gas pressure infiltration. The fabrication temperature of the preforms was $500^{\circ} \mathrm{C}$ and that of the $\mathrm{AC} 4 \mathrm{C}$ aluminium melt was $780^{\circ} \mathrm{C}$. The gas pressure of $2 \mathrm{MPa}$ was applied by argon and kept for $2 \mathrm{~min}$. Soon after the infiltration, the composites were moved out of the furnace and cooled to room temperature. The volume fractions of SCFs in these composites were nearly $24 \%$. Some of the as-cast composites were then extruded with diameter of $37.5-8 \mathrm{~mm}$ at $450^{\circ} \mathrm{C}$ to obtain as-extruded composites.

\subsection{Characterization}

The DSC-TGA curves of the as-received SCFs, SCF preforms and alumina-coated SCF preforms from room temperature to $1000^{\circ} \mathrm{C}$ were characterized using a SDT Q600 DSC instrument. A heating rate of $10^{\circ} \mathrm{C} \mathrm{min}{ }^{-1}$ was used. The crystalline state of the alumina coating and phase composition of the composites were characterized by X-ray diffraction (XRD) using a D/max-2550 instrument $(\mathrm{Cu} \mathrm{K} \alpha)$. A scan speed of $4^{\circ} \mathrm{min}^{-1}$ was used in the range of $10^{\circ}-90^{\circ}$ to study the comprised phases, while a scan speed of $0.25^{\circ} \mathrm{min}^{-1}$ was used in the range of $30^{\circ}-37^{\circ}$ to determine the formation of $\mathrm{Al}_{4} \mathrm{C}_{3}$. The compressive strengths of the $\mathrm{SCF}$ preform and alumina-coated SCF preform were measured using a SANS Compression Testing Machine. The morphology of the alumina coating and microstructures of the preforms and composites were observed by scanning electron microscopy (SEM) using a FEI Quanta FEG 250 SEM at $20 \mathrm{kV}$ and transmission electron microscope (TEM) using a JEOL 2100F Field Emission Electron Microscope. The CTE values of the specimens $\left(\Phi 6 \times 25 \mathrm{~mm}^{2}\right)$ were measured using a dilatometer
(NETZCH DIL 402C) from room temperature up to $300^{\circ} \mathrm{C}$. The TC values of the specimens $\left(\Phi 6 \times 35 \mathrm{~mm}^{2}\right)$ were characterized using a NETZCH TCT 416.

\section{Results and discussion}

\subsection{Characterization of alumina coating}

Figure $2 \mathrm{~b}$ shows the XRD profiles of the boehmite gel and alumina coating. From figure $2 \mathrm{a}$ and $\mathrm{b}$, we can figure out the formation process of $\alpha-\mathrm{Al}_{2} \mathrm{O}_{3}$ coatings. Boehmite sol was dried to form amorphous boehmite and then the obtained boehmite was calcined at $1000^{\circ} \mathrm{C}$ to obtain $\alpha-\mathrm{Al}_{2} \mathrm{O}_{3}$ coatings.

Figure 3 shows the morphologies of the alumina coating on carbon fibres prepared using boehmite sol with PVA and boehmite of different concentrations. The boehmite sol used for figure $3 a, c$ and e has no PVA while that used for figure $3 b$, $\mathrm{d}$ and $\mathrm{f}$ has $1 \mathrm{wt} \%$ PVA. As shown in figure $3 \mathrm{a}, \mathrm{c}$ and $\mathrm{e}$, the alumina coatings are not uniform, with some local areas even uncoated. In contrast, the alumina coatings in figure $3 \mathrm{~b}, \mathrm{~d}$ and $f$ are relatively more uniform and integrated, which is probably caused by the existence of PVA. PVA can adsorb the particles in the sol and hinder their agglomeration. Thus, it can improve the homogeneity of the boehmite sol, which leads to uniform alumina coatings.

As shown in figure $3 \mathrm{a}$ and $\mathrm{b}$, for boehmite sol with concentration of $0.3 \mathrm{~mol}^{-1}$, the alumina coatings are mainly located at the ravines of the carbon fibres. When the concentration increases to $0.4 \mathrm{~mol} \mathrm{l}^{-1}$ (figure $3 \mathrm{c}$ and d), the alumina coatings become more integrated. Particularly, in figure $3 \mathrm{~d}$, the alumina coating covers almost the whole surface of the carbon fibres. For $0.5 \mathrm{~mol} \mathrm{l}^{-1}$ boehmite sol (figure $3 \mathrm{e}$ and $\mathrm{f}$ ), the alumina coatings become discontinuous and easily fall off. Therefore, the most suitable concentration should be $0.4 \mathrm{~mol}^{-1}$. This can be explained as follows. When the concentration is low, the boehmite sol has high fluidity and low 

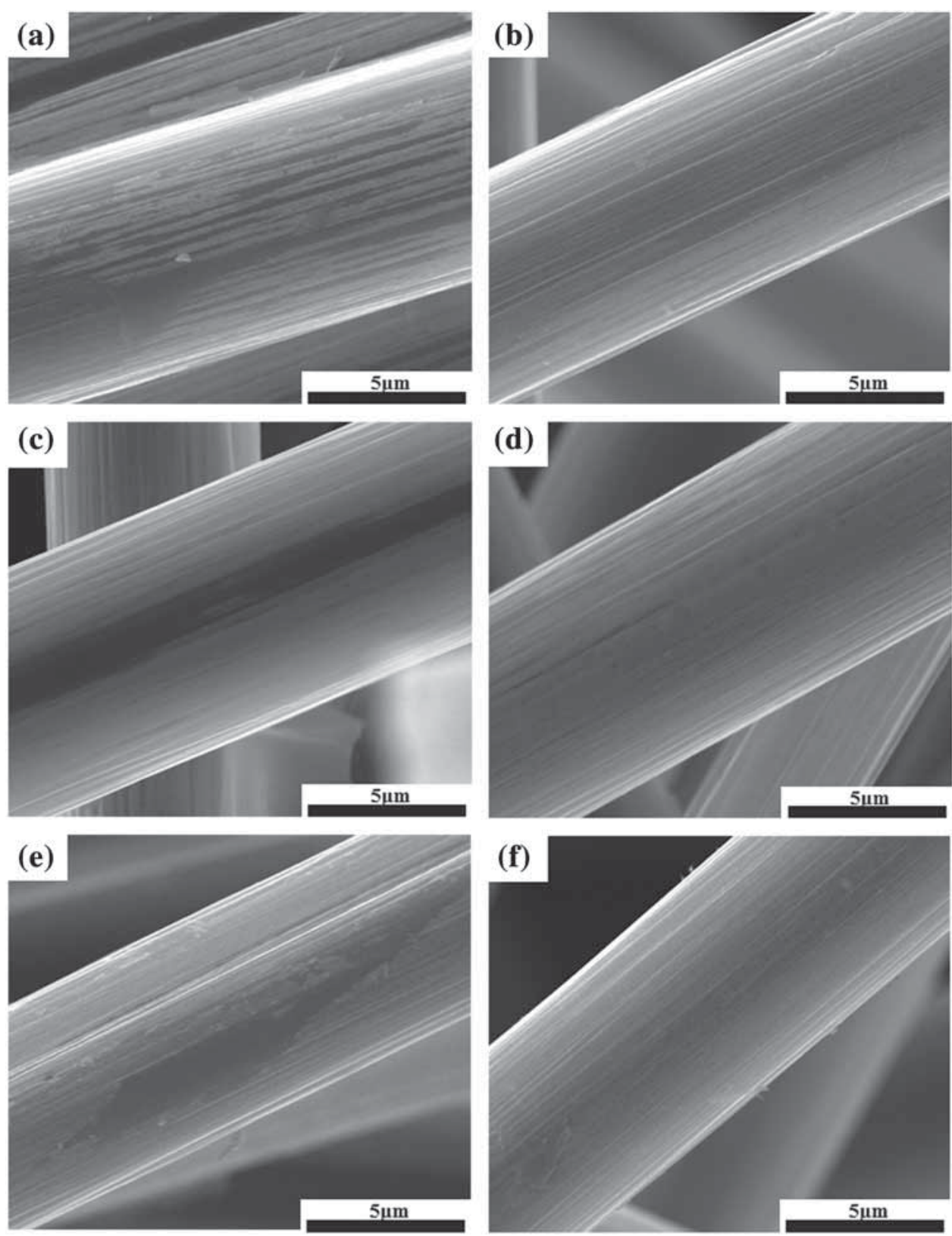

Figure 3. Morphologies of the alumina coating with different concentrations of boehmite sol and PVA: (a) $0.3 \mathrm{~mol} \mathrm{1}^{-1}$, no PVA; (b) $0.3 \mathrm{~mol} \mathrm{l}^{-1}, 1 \%$ PVA; (c) $0.4 \mathrm{~mol} \mathrm{l}^{-1}$, no PVA; (d) $0.4 \mathrm{~mol} \mathrm{l}^{-1}$, $1 \%$ PVA; (e) $0.5 \mathrm{~mol}^{-1}$, no PVA and (f) $0.5 \mathrm{~mol}^{-1}, 1 \%$ PVA.

viscosity. The particles in the sol concentrate in the ravines of the carbon fibres, where sol adsorption is the easiest. With increasing concentration, the viscosity of the sol increases, which leads to integrated coatings. However, if the concentration is too high, the obtained coating will be too thick, which makes it easy to fall off due to the thermal stress generated in the preparation process.

Therefore, $0.4 \mathrm{~mol}^{-1}$ boehmite sol with $1 \%$ PVA is chosen as the best sol composition for coating process, at which integrated coatings with appropriate thickness can be fabricated.

\subsection{Effect of alumina coating}

The microstructures of the fracture surface of the SCF preforms and alumina-coated SCF preforms are shown in figure 4 . As shown in figure $4 \mathrm{~b}$ and d, for both SCF preforms and alumina-coated SCF preforms, carbon fibres connect with each other by binders to form an preform with sufficient strength for infiltration. However, as demonstrated in figure 4e, alumina-coated SCF preform has a higher compressive strength than SCF preform (3.2 vs. $2.1 \mathrm{MPa}$ ), which indicates that alumina binder is superior to phosphate binder. Therefore, 

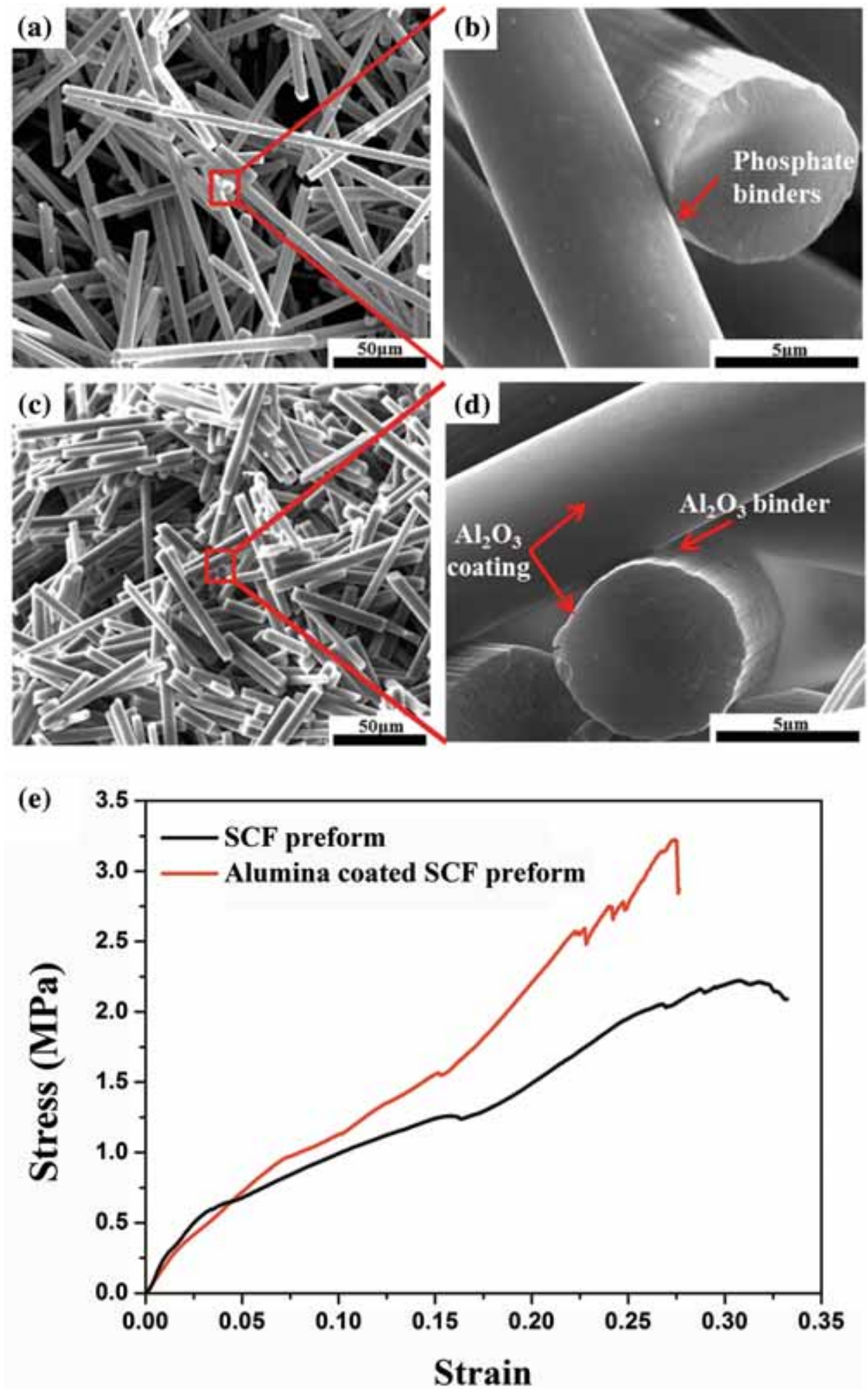

Figure 4. Microstructures of the fracture surface of the preforms. SCF preform: (a) distribution of SCFs and (b) connection between SCFs. Alumina-coated SCF preforms: (c) distribution of aluminacoated SCFs; (d) connection between alumina-coated SCFs and (e) compressive strength of the SCF preforms and alumina-coated SCF preforms. 

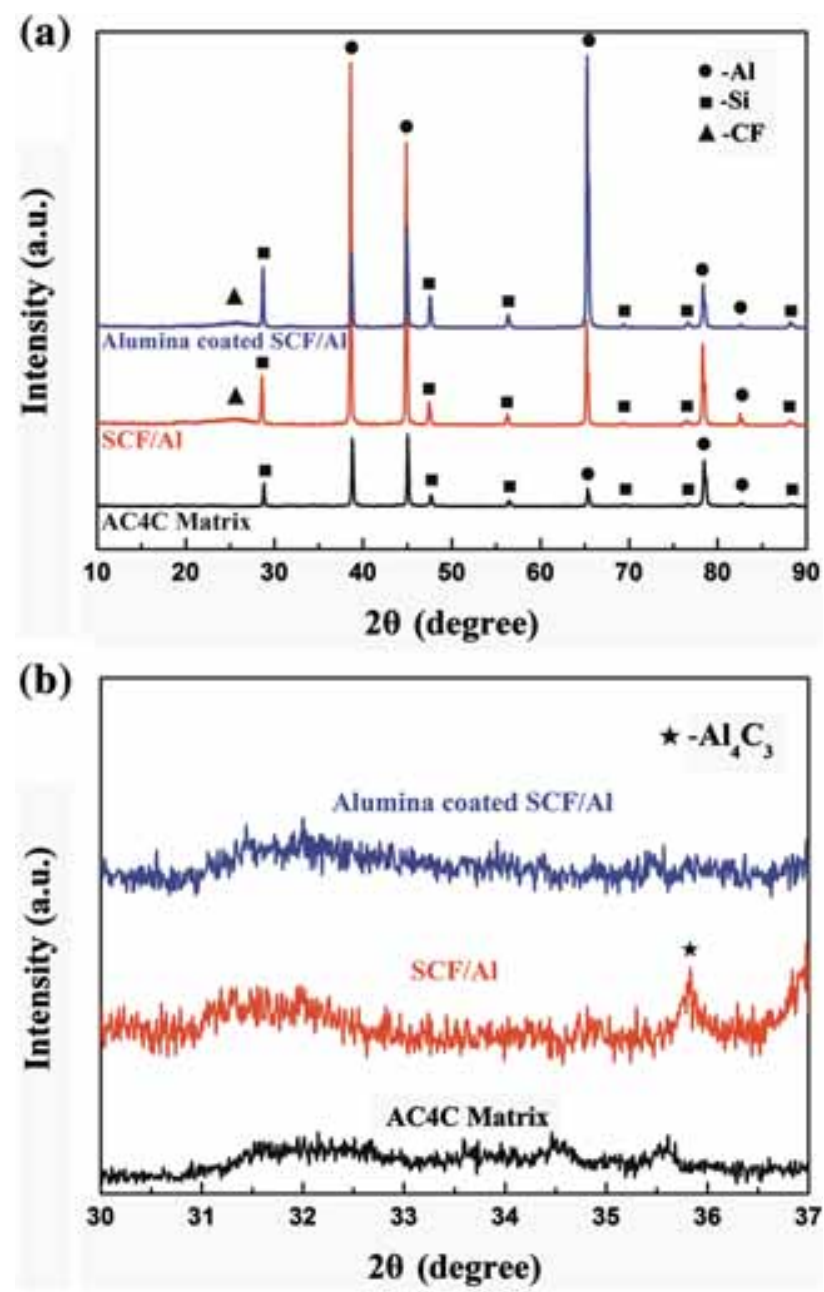

Figure 5. (a) XRD patterns of $\mathrm{AC} 4 \mathrm{C}$ matrix, $\mathrm{SCF}-\mathrm{Al}$ and aluminacoated $\mathrm{SCF}-\mathrm{Al}$ composites and (b) the corresponding XRD patterns showing the formation of $\mathrm{Al}_{4} \mathrm{C}_{3}$ in the $2 \theta$ range of $30^{\circ}-37^{\circ}$. alumina coating can strongly connect the carbon fibres with each other to obtain high quality preforms, which is the basis of composites with superior properties.

Figure 5a shows the XRD profiles of AC4C matrix, SCF$\mathrm{Al}$ and alumina-coated SCF-Al composites. Peaks of $\mathrm{Al}$ and $\mathrm{Si}$ can be detected in these profiles. Composite samples have amorphous-like peak between $24^{\circ}$ and $28^{\circ}$, which is the peak of carbon fibres. Unfortunately, none of the peaks could be indexed as $\mathrm{Al}_{4} \mathrm{C}_{3}$ in the range of $10^{\circ}-90^{\circ}$ at a scan speed of $4^{\circ} \mathrm{min}^{-1}$, which is probably because the content of $\mathrm{Al}_{4} \mathrm{C}_{3}$ formed is too limited to be detected at such a high scanning speed. In order to determine the presence of the reaction product, the composites were further examined by XRD with a much lower scan speed of $0.25^{\circ} \mathrm{min}^{-1}$ in the range of $30-37^{\circ}$, in which the characteristic peaks of $\mathrm{Al}_{4} \mathrm{C}_{3}$ are included. The corresponding XRD patterns are shown in figure 5b. Peaks of the $\mathrm{Al}_{4} \mathrm{C}_{3}$ can be found in the pattern of SCF-Al composites, while no obvious peaks of $\mathrm{Al}_{4} \mathrm{C}_{3}$ can be detected in the pattern of alumina-coated SCF-Al composites. This indicates that alumina coating can impede the interfacial reactions of the SCF-Al composites.

Figure 6a shows the TEM micrograph and selected area diffraction (SAD) patterns (inset) of the interface of the SCF$\mathrm{Al}$ composites. The presence of needle-like phase and its high resolution TEM (HRTEM) image (see figure 6b) indicate that $\mathrm{Al}_{4} \mathrm{C}_{3}$ has formed at the interface, which is in agreement with the XRD results as shown in figure 5. In contrast, clean and fine interfaces are observed in the alumina-coated $\mathrm{SCF}-\mathrm{Al}$ composites, as shown in figure 7a. The SAD patterns of aluminium, alumina coating and carbon fibre are shown in figure $7 \mathrm{~b}, \mathrm{c}$ and $\mathrm{d}$, respectively. The alumina coating is uniform and integrated, and its thickness is about $200 \mathrm{~nm}$. The alumina coating successfully acts as a diffusion barrier between aluminium and carbon fibres, which impedes

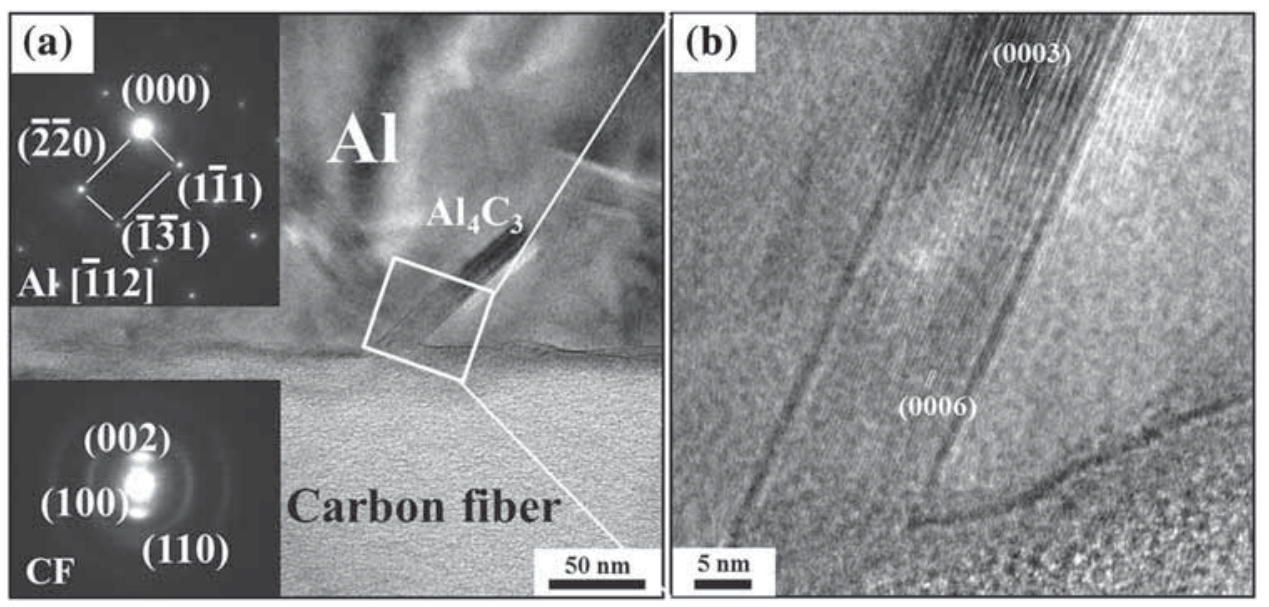

Figure 6. Typical TEM image, SAD patterns and HRTEM image of the interfaces of the SCF-Al composites: (a) interfacial microstructure; inset: SAD pattern of Al matrix and SCF and (b) HRTEM image of $\mathrm{Al}_{4} \mathrm{C}_{3}$ reaction product. 


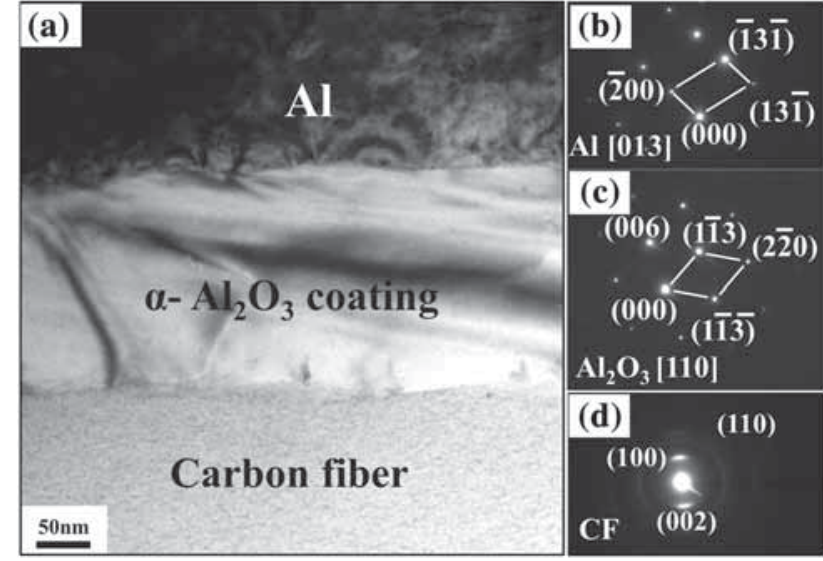

Figure 7. Typical TEM image and SAD patterns of the interfaces of the alumina-coated SCF-Al composites: (a) interfacial microstructure and $\mathrm{SAD}$ pattern of $(\mathbf{b}) \mathrm{Al}$ matrix; (c) $\mathrm{Al}_{2} \mathrm{O}_{3}$ coating and (d) SCFs.

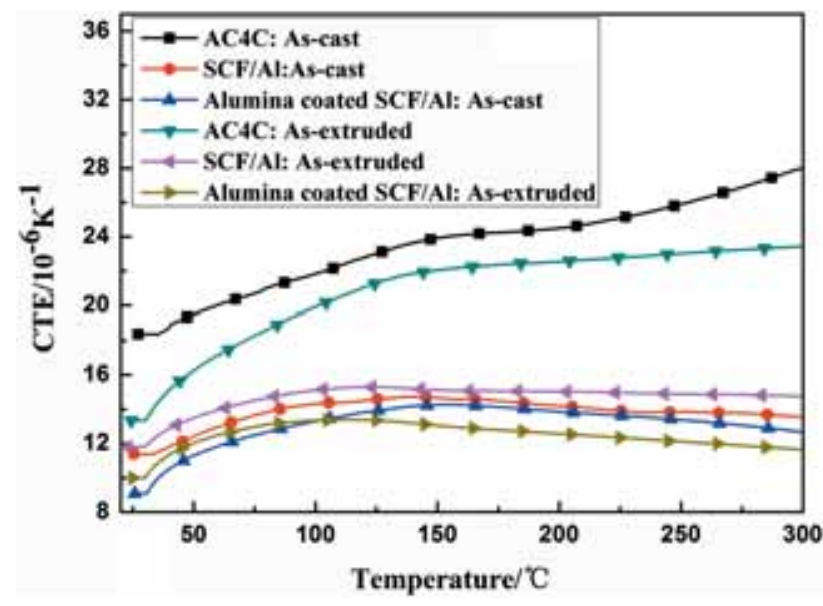

Figure 8. CTE values of the as-cast and as-extruded AC4C matrix, $\mathrm{SCF}-\mathrm{Al}$ and alumina-coated $\mathrm{SCF}-\mathrm{Al}$ composites.

the harmful chemical reactions between aluminium and carbon fibres.

The CTE values of the as-cast and as-extruded AC4C matrix, $\mathrm{SCF}-\mathrm{Al}$ and alumina-coated $\mathrm{SCF}-\mathrm{Al}$ composites are shown in figure 8 . The CTE values of the composites are much lower than that of the corresponding matrix. This is due to the existence of low-CTE SCFs. The CTE values of the alumina-coated $\mathrm{SCF}-\mathrm{Al}$ composites are less than that of the SCF-Al composites for both as-cast and as-extruded samples, which indicates that alumina coatings have a beneficial effect on the improvement of dimension stability of the composites. This can be explained by two reasons. Firstly, according to the results of XRD patterns (figure 5) and TEM micrographs (figure 7), alumina coating can act as a diffusion barrier to protect the SCFs from being damaged by reaction with aluminium matrix, which leads to lower CTE of the composites.

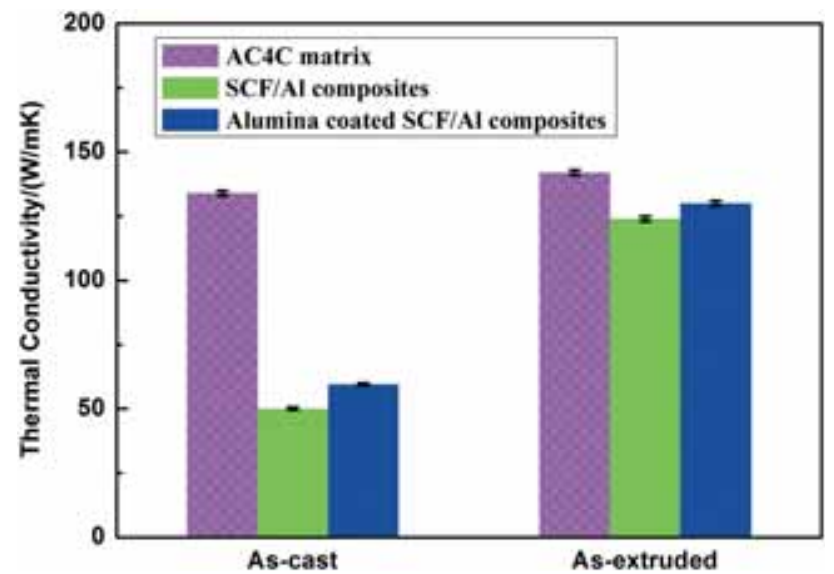

Figure 9. TC values of the as-cast and as-extruded AC4C matrix, $\mathrm{SCF}-\mathrm{Al}$ and alumina-coated $\mathrm{SCF}-\mathrm{Al}$ composites.

Secondly, the CTE value of the alumina coating is very low (about $7.4 \times 10^{-6} \mathrm{~K}^{-1}$ ) [22].

As show in figure 9, for both as-cast and as-extruded samples, the TC values of the alumina-coated SCF-Al composites are higher than that of the SCF-Al composites. On one hand, $\mathrm{TC}$ value of the alumina coating is relatively low (nearly $36 \mathrm{~W} \mathrm{~m}^{-1} \mathrm{~K}^{-1}$ [23]), which may have a bad effect on the improvement of TC of the composites. On the other hand, alumina coating can act as the diffusion barrier to reduce the formation of $\mathrm{Al}_{4} \mathrm{C}_{3}$, which is harmful to $\mathrm{TC}$ of the composites [12]. Therefore, the result of this study shows that the beneficial effect dominates the effect of alumina coating on TC values of the composites. The composites have lower TC values than that of the corresponding matrix because TC value of the T300 carbon fibres used in this study is relatively low (about $8 \mathrm{~W} \mathrm{~m}^{-1} \mathrm{~K}^{-1}$ ) [24].

In summary, alumina coating can not only improve the quality of the preforms but also impede the formation of harmful $\mathrm{Al}_{4} \mathrm{C}_{3}$ at the interface of the composites. Therefore, it can reduce the CTE values, meanwhile improving the TC values of the composites.

\subsection{Effect of extrusion deformation}

Figure 10 shows the microstructures of the as-cast and asextruded composite samples. As shown in figure 10a, most of the carbon fibres in the as-cast composites intersect rather than being parallel to the observing plane. The orientations of the carbon fibres are disordered. Some of the carbon fibres are very close to each other, which is in agreement with the microstructure of the preform as shown in figure 4. In addition, large blocks of Si phases can be found in the ascast composites. In contrast, most of the carbon fibres in the as-extruded composites are nearly oriented along the extrusion direction as shown in figure 10b. However, on comparing figures 10 and 4 , one can find that the aspect ratio of the carbon fibres decreases drastically after extrusion 


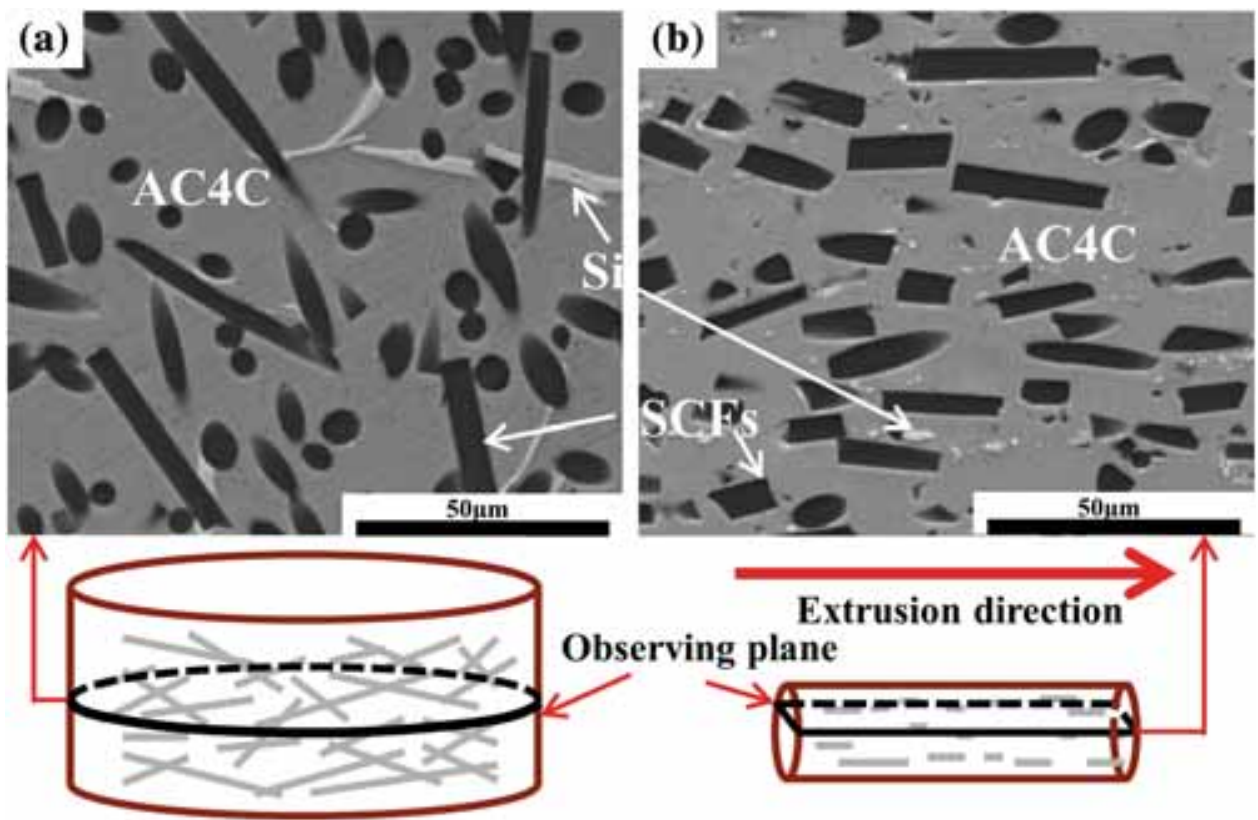

Figure 10. Microstructures of the SCF-Al composites: (a) as-cast and (b) as-extruded.

(from 14.3 to 2.5), which indicates that carbon fibres have been broken off during extrusion. The large Si phases also broken into small blocks.

As shown in figure 8, the CTE values of the SCF-Al composites increase after extrusion. However, the curves of the CTE values of the as-cast and as-extruded alumina-coated $\mathrm{SCF}-\mathrm{Al}$ composites cross each other at nearly $110^{\circ} \mathrm{C}$. Therefore, it is hard to predict which state is better for improving the dimensional stability. This is mainly because extrusion deformation can not only orient the carbon fibres in the extrusion direction but also decrease the aspect ratio of the carbon fibres, as shown in figure 10. The CTE values of composites decrease with the increase of oriented carbon fibres but increase with the decrease of the aspect ratio of the carbon fibres. It is worth noting that the differences between the ascast and as-extruded samples for both SCF-Al composites and alumina-coated $\mathrm{SCF}-\mathrm{Al}$ composites are relatively small (about $1 \times 10^{-6} \mathrm{~K}^{-1}$ ), which indicates that the effect of extrusion deformation on CTE of the composites is small due the reason that the effect of improvement of degree of orientation and decrease of aspect ratio of carbon fibres tend to cancel each other out somewhat.

As shown in figure 9, it is obvious that the as-extruded composites have much higher TC values than the as-cast composites, which indicates that extrusion deformation has a beneficial effect on the improvement of the TC of the composites. In order to have a better understanding of the reasons for this phenomenon, a schematic diagram of the transfer of heat flow is shown in figure 11. The heat flow in the ascast composites may pass through more low-TC carbon fibre obstacles than those in the as-extruded composites. What is more, in the as-extruded composites, the carbon fibres are nearly oriented along the heat conduction direction. On the

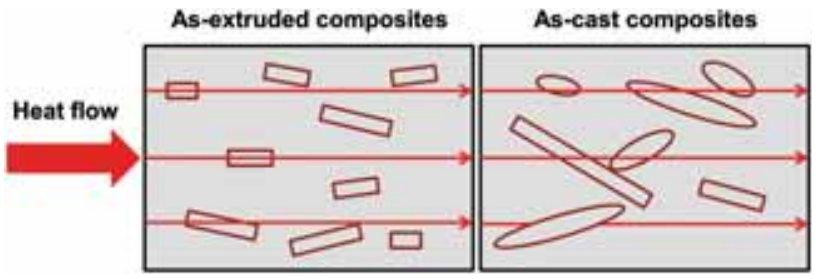

Figure 11. Schematic diagram for explanation of the effect of extrusion on TC values of the composites.

contrary, the orientations of the carbon fibres in the as-cast composites are disordered. Since the TC value along the axial direction of the carbon fibres is higher than that along the other directions [24], the as-extruded composites can provide a smoother way for the conduction of heat flow. Therefore, the TC values of the as-extruded composites are much higher than that of the as-cast composites.

\section{Conclusion}

SCFs were coated with $\alpha-\mathrm{Al}_{2} \mathrm{O}_{3}$ coating by a sol-gel process. $\mathrm{SCF}-\mathrm{Al}$ and alumina-coated $\mathrm{SCF}-\mathrm{Al}$ composites were fabricated by gas pressure infiltration. The effects of alumina coating and extrusion deformation on microstructures and thermal properties of the $\mathrm{SCF}-\mathrm{Al}$ composites were studied. Based on our results, the following conclusions are drawn:

(1) By the sol-gel coating process used in this study, the carbon fibres can be coated with uniform and integrated alumina coating with thickness of nearly 200 $\mathrm{nm}$. The optimized sol composition for coating process is $0.4 \mathrm{~mol}^{-1}$ boehmite sol with $1 \%$ PVA. 
(2) Alumina coating can not only improve the quality of the preforms but also impede the formation of harmful $\mathrm{Al}_{4} \mathrm{C}_{3}$ at the interface of the composites and protect the SCFs from being damaged by interfacial reactions. Therefore, it exhibits a beneficial effect on reducing the CTE values, meanwhile improving the TC values of the SCF-Al composites.

(3) Extrusion deformation can orient SCFs to the extrusion direction, but it can also decrease the aspect ratio of the SCFs. Extrusion deformation has a beneficial effect on TC of the SCF-Al composites mainly due to the reason that it can orient SCFs to the extrusion direction. However, the effect of extrusion deformation on $\mathrm{CTE}$ of the SCF-Al composites is the hybrid effects of improvement in degree of orientation and decrease of aspect ratio of SCFs. In this study, these two effects tend to cancel each other out somewhat, which leads to a slight change in the CTE of the SCF-Al composites after extrusion deformation.

\section{Acknowledgements}

We would like to sincerely acknowledge the financial supports of the National Natural Science Foundation of China (numbers 51471106, 51501111 and 51671129), the National Basic Research Program (number 2012CB619600) and the Foundation of Shanghai Science and Technology Committee of China (numbers 14DZ2261200 and 14520710100).

\section{References}

[1] Chung D 1994 Carbon fiber composites (Boston: ButterworthHeinemann)
[2] Shekar K C, Priya M S, Subramanian P K, Kumar A, Prasad B A and Prasad N E 2014 Bull. Mater. Sci. 37597

[3] Liu Y and Qiang C 2015 Bull. Mater. Sci. 381673

[4] Huang Y, Ouyang Q, Zhang D, Zhu J, Li R and Yu H 2014 Acta Metall. Sin. (Engl. Lett.) 27775

[5] Urena A, Rams J, Escalera M and Sánchez M 2007 Compos. Part A 381947

[6] Liu T, He X, Zhang L, Liu Q and Qu X 2014 J. Compos. Mater. 482207

[7] Kainer K U 2006 Metal matrix composites (Weinheim: Wiley$\mathrm{VCH})$

[8] Lin T, Jia D, Wang M, He P and Liang D 2009 Bull. Mater. Sci. 3277

[9] Sánchez M, Rams J and Ureña A 2010 Compos. Part A 41 1605

[10] Bhav Singh B and Balasubramanian M 2009 J. Mater. Process. Technol. 2092104

[11] Lancin M and Marhic C 2000 J. Eur. Ceram. Soc. 201493

[12] Lee M, Choi Y, Sugio K and Matsugi K 2000 Compos. Sci. Technol. 971

[13] Steffens H-D, Reznik B, Kruzhanov V and Dudzinski W 1997 J. Mater. Sci. 325413

[14] Vidal-Setif M, Lancin M, Marhic C et al 1999 Mater. Sci. Eng. A 272321

[15] Rajan T, Pillai R and Pai B 1998 J. Mater. Sci. 333491

[16] Peng P, Li X, Yuan G et al 2001 Mater. Lett. 47171

[17] Zeng Q 1998 J. Appl. Polym. Sci. 70177

[18] Tang Y, Liu L, Li W, Shen B and Hu W 2009 Appl. Surf. Sci. 2554393

[19] Tang Y, Deng Y, Zhang K, Liu L, Wu Y and Hu W 2008 Ceram. Int. 341787

[20] Cai J, Chen Y, Nesterenko V F and Meyers M A 2008 Mater. Sci. Eng. A 485681

[21] Chiou J M and Chung D 1993 J. Mater. Sci. 281435

[22] Hassan S and Gupta M 2005 Metall. Mater. Trans. A 362253

[23] Cheng J P, Liu T, Zhang J et al 2014 Appl. Phys. A 1171985

[24] Koráb J, Štefánik P, Kavecký Š, Šebo P and Korb G 2002 Compos. Part A 33577 